\title{
Three Fallacies about Action
}

\author{
JOHN HYMAN, OXFORD
}

1.

The main purpose of this article is to criticize three closely related fallacies, which have shaped philosophical ideas about action throughout the modern period: first, the idea that all action is human action, so that human beings are sometimes active and sometimes passive, but everything else in the world is always passive; second, the assumption that the distinction between active and passive coincides with the distinction between voluntary and not voluntary; and third, the thought that action is a kind of motion, for example, motion in a special context or with a special cause. However, before I get to the main business, I shall say something about what action is.

\section{2.}

What is action? We distinguish action from thought, when we contrast an active life and a contemplative life; we compare it with speech and writing, when we say that actions speak louder than words; and we contrast it with passion, by which we do not mean intense feeling, but rather enduring, undergoing - or, in an antiquated use of the word, suffering - change. All of these comparisons point to the same idea. To act is to intervene, to make a difference, to bring about or cause some kind of change. ${ }^{1}$ The change may be momentous or trivial. It may be a kind of motion, as when one opens or closes a door or throws a ball. Or another kind of change may be involved, as when one melts a knob of butter in a pan or burns some toast. What runs like a thread through our thought and talk about action is the idea of making a difference, or causing change.

The concept of action is correlative with the concept of agency: for actions are by agents, and agents act. Furthermore, just as action is contrasted with passion, agents are contrasted with patients, and active powers are contrasted with passsive powers. Agents bring about or cause change, whereas patients undergo or suffer change; active powers are abilities to cause change, whereas passive powers are liabilities to undergo change.

\footnotetext{
${ }^{1}$ One can also make a difference by preventing change. See below, section (3).
} 
For example, when Paul melts a knob of butter in a pan, Paul is the agent and the knob of butter is the patient. Paul exercises his ability to bring about the change the butter undergoes, and the butter realizes its liability to undergo the change Paul brings about. If we use the verb in the active voice to report the action-'Paul melted the butter'-the subject of the verb refers to the agent and the object of the verb refers to patient. If we use the verb in the passive voice-'The butter was melted by Paul'- the subject of the verb refers to the patient and the agent is referred to in the complement 'by Paul'.

However, we cannot simply divide the world into agents and patientsfor example, we cannot say that human beings are agents whereas knobs of butter are patients - because one is an agent or a patient only in relation to a particular action. For example, a boxer is an agent in relation to a punch he lands on his opponent, but he is a patient in relation to a punch his opponent lands on him. Equally, if A causes B to perform a certain actionfor example, if $\mathrm{A}$ frogmarches $\mathrm{B}-\mathrm{B}$ is a patient in relation to A's action and an agent in relation to his own. ${ }^{2}$ It is even possible to be both agent and patient in relation to a single action. For example, a man who commits suicide is both agent and patient: as the one who kills, he is an agent; as the one who dies, he is a patient. One way of making this point is to say that 'agent' and 'patient' do not refer to kinds of beings, but to rôles.

The range of verbs used to report actions is vast and varied, because agents cause a vast range of different kinds of change, and because many verbs used to report actions do more than merely identify the kind of change the agent caused. For example, to kill something is to cause its death. (A few writers have denied this, but their reasons for doing so are very weak. I shall return to this point in section (4).) So the sentence 'Cain killed Abel' simply means that Cain caused Abel's death. The verb does not tell us whether he did it knowingly or unknowingly, quickly or slowly, with a stone or with a knife. By contrast, 'Cain murdered Abel' means that Cain killed Abel wickedly or unlawfully, and 'Cain assassinated Abel' means that Cain killed Abel with treacherous violence.

However, even these last two examples are straightforward illustrations of the idea that to act is cause some kind of change, because we can paraphrase the sentences 'Cain murdered Abel' and 'Cain assassinated Abel' in the form 'Cain caused Abel's death \{adverb/adverbial phrase\}'. English is not always so cooperative. For example, 'Cain kicked Abel' evidently re-

\footnotetext{
${ }^{2}$ As this example indicates acting includes causing action as well as directly causing change.
} 
ports an action. But although it is easy enough to explain what kicking something is, the simplest explanation-e.g. kicking something is striking it with one's foot - does not combine the verb 'cause' with a phrase describing the change that someone who kicks something causes.

We use a vast range of verbs to report actions. Some refer implicitly to legal, moral or psychological dimensions of the action, while other do not, and some are easy to paraphrase in a form which says explicitly that the agent caused a certain kind of change, while others take more lexical knowledge and more verbal dexterity to unpack. Furthermore, there is no simple or single formula for doing the unpacking, applicable in every case. Obviously, the simplest kind of case is one in which no inessential features of the action are referred to, and we can say immediately what the change the agent causes is. Happily, there is no shortage of such verbs. ${ }^{3}$ We have, for example, 'open', 'close', 'melt', 'burn', 'twist', 'tear', 'raise', 'lower', 'turn' and 'move'. (Readers will not find it difficult to extend this list.)

In each case we find the same pattern. To open a door is to cause it to open; to close a door is to cause it to close; to melt some butter is to cause it to melt; to burn some toast is to cause it to burn; and so on. In each case the verb can occur transitively or intransitively, i.e. with a grammatical object or without one. When it occurs transitively, it is described as causative, because it refers to a kind of action; when it occurs intransitively, it is described as mutative, because it refers to the corresponding kind of change. The existence of the two forms is known as causative/mutative alternation. ${ }^{4}$ It is fortunate that 'move', together with many verbs that refer to specific ways of moving something - e.g. 'raise', 'lower' and 'turn'conform to this pattern, because actions that consist in an agent's moving part of his or her own body - e.g. raising or lowering one's arm or turning one's head-have traditionally played a central rôle in the philosophy of action, as we shall see.

\section{3.}

So we can define an action as the bringing about or causing of some kind of change, the agent being the one that brings about the change and the ptient being the one that undergoes it. This is not a reductive definition. There is no suggestion that the concepts of causation and change are sim-

\footnotetext{
${ }^{3}$ On this topic see Anscombe 1981; Strawson 1992, ch.9.

4 'Inchoative' is sometimes used instead of 'mutative', e.g. in Levin 1993; but 'inchoative' is normally used by grammarians in another sense.
} 
pler than the concept of action itself, or that the concept of action is composed out of these other concepts in the way that a complex molecule is composed out of elements in the periodic table. On the contrary, the aim of defining an action in this way is to show part of how a number of equally abstract ideas are related to each other - notably, the ideas of substance (in the traditional sense of persisting object), power, action, cause and event. It is, to use a term introduced by P.F. Strawson, a connective rather than a reductive definition of action.

So the definition is connective. It is also conservative, by which I mean that it counts a relatively restricted range of phenomena as actions. For example, when I hold my breath, I prevent a certain kind of motion in my body. This performance (to use a neutral term) can be voluntary, intentional, planned, etc., and it might well be described as an action, in the right context. But to prevent motion is to cause it not to occur, so I do not count it as action. ${ }^{5}$ Again, we distinguish between thought and action. But thought is not invariably idle or inactive, even if it is not best thought of as causing change. Is running through a tune in one's head an action? Is remembering a date, or listening attentively to a lecture? Or does thought acquire the status of activity from the larger project it is part of, as when we do the mental arithmetic involved in filling out our tax returns? The definition proposed here does not budget for these kinds of subtleties, and I propose to set them aside.

Defining an action as the bringing about or causing of some kind of change therefore presents a simple, indeed a simplifying, model of our thought - one that distinguishes between causing and preventing change, and between thinking and acting, with unnatural sharpness. It is, in effect, the result obtained by using the concepts of substance, power, action, cause and event to define in abstract terms the common thread that runs through the thought of something raising, lowering, carrying, dragging, throwing, or in general moving something; or making, breaking, heating, cooling, twisting, tearing, or in general creating, destroying or changing something. To return to an example mentioned earlier, Paul and a knob of butter are both substances; Paul is able to melt butter, and butter is liable to melt; the event that has to occur if Paul melts the butter is the butter's melting; and Paul's action is the causing of this event. So a change in one substance (the

\footnotetext{
${ }^{5}$ However, it is possible to prevent $x$ by causing $y$, e.g. to prevent a bath from overflowing by closing the tap. And it is possible to cause $x$ by preventing $y$, e.g. to kill a man by suffocating him.
} 
patient) is caused by another substance (the agent) and the action is the causing of this change.

The model is simple, and its value lies in its simplicity. It is not an exact record of our fluid and undisciplined thought and talk: it regiments it to some degree. But it makes our thought and talk more tractable, and fallacies easier to expose.

It has been objected that this definition of action relies on a false account of the meaning of causative verbs. To open or close something, I said, is to cause it to open or close, to move something is to cause it to move, to kill something is to cause it to die, and so on-whether the thing opened or closed is a door or one's fist, whether the thing moved is one's hand or one's car, and by whatever means the action is performed. But this is disputed. Someone who moves her hand (it is said) does not cause her hand to move, if she moves it directly, that is, without doing so by moving something else. If she moves her hand with a Heath-Robinsonian contraption of some kind, and perhaps if she moves it with her other hand, she causes it to move. But not if she moves it directly. Equally, a man who causes another man's death by hiring an assassin does not kill the man himself. I shall reply to the objection by commenting on these two examples in turn.

Concerning the first example, there is no controversy about whether someone moves her hand both when she does so directly and when she does so indirectly. It is clear, and uncontroversial, that she does. It is also uncontroversial that when she moves her hand with a Heath-Robinsonian contraption, she causes her hand to move. The question is whether she causes her hand to move when she moves it directly. If we equate moving with causing to move, we are bound to say that she does. But this has sometimes been denied, on the grounds that we would not normally say 'She caused her hand to move' in this case, and it would be misleading if we did say it.

The standard reply to this kind of argument is due to Grice. Grice pointed out that we cannot infer from the fact that we would not normally say something, or that it would be misleading to say it, that it is not true. ${ }^{6}$ For example, if we knew that someone had finished his dinner we would not normally say that he had begun it. But it would not be untrue to say this. For if someone has finished his dinner, then he must have begun it.

\footnotetext{
${ }^{6}$ Grice 1989, chs.1-3.
} 
Again, the remark 'Scooter is a lawyer, but for all that he's an honest man' is misleading if in fact most lawyers are honest men. But if Scooter is both a lawyer and an honest man, describing the remark as untrue is not the right way to capture what is wrong with it. Thus, if we grant that we would not normally say of someone who raised her arm directly that she caused it to rise, and that it would be misleading if one did say this, it does not follow that it would be untrue to say it.

This is a defensive reply to the argument. But the main reason for insisting that to open or close something is to cause it to open or close, to move something is to cause it to move, and so on, is simply that there is no other plausible way of explaining what these causative verbs mean, and how their meaning when they occur transitively is related to their meaning when they occur intransitively. For example, to move is to change one's posture, position or location; to move something is to change its posture, position or location; and to change something is to cause it to change: as the OED puts it, it is to make something - i.e. cause it to become-other than it was. Every dictionary says this, or something very like it, and it is hard to think of a plausible definition which is substantially different from this one.

We should therefore insist that to move something simply is to cause it to move, regardless of what is moved or how it is moved, while acknowledging that we tend to reserve the phrase 'cause ... to move' ('... to open, close, etc.') for the case where something is moved (opened, closed, etc.) indirectly, e.g. with a lever or a machine. This is preferable to denying (as some philosophers have done) that it is possible to explain what verbs such as 'move' mean. 'Alternatively, we can assign the role of expressing the broader causal concept to the phrase 'bring about', and say instead that to move something simply is to bring it about that it moves-regardless of what is moved or how it is moved-while allowing that to cause something to move is to bring it about indirectly that it moves. This concession only requires a terminological adjustment to the position defended here, but I do not believe it is necessary.

What about the contract killing? If to kill something simply is to cause it to die, and if the man who hires an assassin causes his victim to die, then the man kills his victim. But surely (it is said) we would normally say that the assassin is the one who kills him.

My reply to this objection is that we certainly must distinguish between the case where A kills B himself, and the case where A employs or induces

\footnotetext{
${ }^{7}$ Fodor 1976, 130n.
} 
$\mathrm{C}$ to kill $\mathrm{B}$ on his behalf; but we are not obliged to do this by confining the use of the causative verb to the first case, and as a matter of fact our use of causative verbs is less disciplined than this. We are comfortable saying that Louis XIV built Versailles, that Hitler bombed London and that Stalin killed millions, while acknowledging that they did not do these things personally or with their own bare hands. We can if we wish say-with deliberate emphasis - 'But the man who hires an assassin doesn't actually (or, as philosophers sometimes say, strictly speaking) kill his victim', and perhaps this will be agreed. But if so, it will be agreed because it is understood that by 'actually kill' or 'strictly speaking kill', what is meant is kill personally or with his own bare hands.

I conclude that the definition of action proposed here-viz. that to act is to bring about or cause some kind of change - is consistent with the way in which we use causative verbs. The contrary view depends on an artificially disciplined account of how these verbs are used, coupled with a tendency to misunderstand the significance of this pattern of use. Furthermore, it makes causative/mutative alternation and the meaning of verbs such as 'move' seem baffling, when in fact these things could scarcely be simpler to explain.

I shall now turn to the main business of this article, which is to examine the three fallacies about action introduced in section (1).

\section{5.}

Most philosophers who write about action write exclusively about human action. Indeed many philosophers either claim or assume that human beings are the only real agents that exist, and that human actions are the only real actions there are. ${ }^{8}$ According to this view, when a man pumps water from a well or melts some butter in a pan, these really are actions; but when a man's heart pumps blood around his body or the sun melts some butter on the kitchen table, these are not really actions. This has been the predominant view ever since the nature of action became a lively and controversial topic in twentieth-century philosophy, more than forty years ago. As we shall see, it stems originally from seventeenth-century ideas.

Our innocent, untutored conception of agency and activity is more liberal. We extend it without hesitation to bodily organs, non-human animals, plants and inaninimate substances, whether natural or artificial. For exam-

\footnotetext{
${ }^{8}$ That this view retains the status of an orthodoxy today is due especially to Davidson. See especially 'Agency', in Davidson 1980, ch.3.
} 
ple, we say that beavers build dams and that wasps make nests, and we think of these activities as just that-activities - no less than building houses or making cars. We say that a tree sucks up moisture from the ground and that the wind bends the branches of the tree, and again we think of sucking and bending as making things happen, as bringing about or causing change. Indeed, we often describe inanimate substances as agents of one sort or another, with their own distinctive active powers. For example, soap is a detergent, that is, a cleansing agent, cortisone is an antiinflammatory agent, and so on.

Our untutored conception of agency and activity is therefore at odds with the view held by most philosophers today. This is not merely a difference in the use of words. Philosophers do not think of themselves as having introduced a special, technical sense of the words 'agent' and 'action', with a narrower scope than they have in their usual, non-technical sense; and non-philosophers do not think of themselves as using these words metaphorically. So why does the difference exist? Is it because our innocent, untutored ways of speaking and thinking are careless or informed by a false conception of the way non-human beings behave? For example, it is sometimes said that an animistic or anthropomorphic tendency, deeply rooted in our nature, makes us inclined to endow animals, plants and even mountains, rivers and the wind with thoughts, intentions, plans and purposes. Is this the right explanation?

I do not believe it is. If action necessarily involved thought or intention, a verb used to report an action would include the idea of thought or intention in its meaning. For example, the verb 'build' would attribute thought or intention to the one that builds, and the verb 'cook' would attribute thought or intention to the one that cooks. Hence, these verbs could not be used unambiguously to refer to action, on the one hand, and to the behaviour of animals incapable of thought, or to bodily organs, on the other. But no such ambiguity exists. 'Grind' has exactly the same meaning, whether it refers to a cook grinding meat or a bird's gizzard grinding seeds; 'bend' has the same meaning whether it describes a blacksmith or the wind; and 'build' has the same meaning in the sentences 'Paul built a shed' and 'The wasps built a nest'.

"But if we were told that Paul had built a shed, we would normally assume that he knew what he was doing; whereas if we were told that a swarm of wasps had built a nest, we would not - or at least should notmake the same assumption." True. But this is not because the verb 'build' is ambiguous, involving the idea of thought or intention in one meaning 
and not the other. It is because we know that a human being is generally aware of what he is doing when he builds a shed. In the same way, if we were told that the Pope walked across St. Peter's Square, we would normally assume that he was wearing clothes, whereas we would not make this assumption if we were told that a cat walked across the garden. But this is not because 'walked' is ambiguous, involving the idea of clothing in one meaning and not the other.

I do not mean to deny that we think carelessly or anthropomorphically about many things: no doubt we do. P.F. Strawson mentions an example. If we see a great boulder roll down a mountainside and flatten a wooden hut in its path, he writes, we may, 'in some barely coherent way, identify with the hut (if we are one kind of person) or with the boulder (if we are another): putting ourselves imaginatively in the place of one or the other.' But, he adds, our tendency to do this, if we have such a tendency, has no bearing whatever on our rationale for thinking of the boulder's flattening the hut as an action on a par with vastly many other actions and interactions, which, "whether entered into by animate or inanimate beings ... supply wholly satisfactory explanations of their outcomes, of the states of affairs in which they terminate. 9

Some kinds of action necessarily involve thought or intention, and some verbs of action therefore include the idea of thought or intention in their meaning. For example, to murder is to kill wickedly or unlawfully. So if we think of a shark as murderous, either we are thinking metaphorically or analogically, or we are confused. But reflecting on this kind of case should help us to see that there is nothing either metaphorical or confused in the thought that sharks kill, rather than murder, that wasps build nests, that a tree sucks up moisture, or that the wind bends the tree's branches. These thoughts do not involve the idea that sharks, wasps, trees or the wind have intentions, purposes or plans. They do of course involve the idea that these things do not merely undergo change, but actually cause or bring about change. But causing change is not intentional or purposeful as such.

Our willingness to think of non-human beings as agents is neither careless nor anthropomorphic. On the contrary, confining agency to human beings is absurdly provincial. Anthony Kenny has emphasized this point: 'wherever we can talk of substances in nature,' he writes, 'wherever we can talk of natural kinds, we can talk also of natural agency and natural powers. ${ }^{10}$ But even this remark underplays the extent of agency, since syn-

\footnotetext{
${ }^{9}$ Strawson 1992, 118.

${ }^{10}$ Kenny $1975,46$.
} 
thetic substances are agents, no less than naturally occurring substances. For example, soap is a natural detergent whereas Persil is a synthetic one (or so I was taught). Of course, philosophers are free to confine the terms 'agency' and 'action' to naturally occurring agents, or to agents that have intentions, if they wish. Indeed, they can confine them to adults and exclude children, or confine them to men and exclude women. But there is no evidence that any intellectual advantage can be gained by doing so.

\section{6.}

I shall turn now to the assumption that the distinction between active and passive coincides with the distinction between voluntary and not voluntary.

I begin with a terminological preliminary. The word 'involuntary' is often defined in dictionaries as the contradictory of 'voluntary', but the actual use of the word is commonly confined to thoughts or changes in the body which a person is unable to control, such as 'an involuntary concurrence of ideas', 'the inuoluntarie running of vrine' or 'the involuntary closing of the eyelids when the surface of the eye is touched'. (All of these examples are taken from the OED's entry for 'involuntary'. (11 Thus, in the actual use of these words, 'involuntary' and 'not voluntary' are not equivalent, and if something is not voluntary, we cannot assume that it must therefore be involuntary. For example, a man who is conscripted into the army is not a volunteer, but he does not join the army involuntarily, in this limited sense. We are now principally concerned with what is and what is not voluntary.

In reality, the voluntary/not voluntary distinction and the active/passive distinction cut across each other. For activity can be either voluntary or not voluntary, and the same is true of passivity. But philosophers have commonly ignored or failed to notice two of these possibilities. On the one hand, they have tended to think about the will exclusively in relation to action. They have not thought about it in relation to feelings we experience or conditions in which we place or find ourselves, or in relation to occasions when we are acted upon. They have thought about voluntary activity, but they have ignored voluntary passivity. On the other hand, activity and vol-

\footnotetext{
11 The distinction between 'involuntary' and 'not voluntary' derives from Aristotle's distinction between actions that are performed unknowingly which we do not regret (ouk hekousia) and ones which we do regret (akousia), but this is not the way in which philosophers now use these terms. (Nicomachean Ethics III.1, 1110b18-12; see Broadie 1991, 126.)
} 
untary activity have commonly been equated, as if activity were always voluntary. So they have ignored activity that is not voluntary. The result is that the active/passive distinction and the voluntary/not voluntary distinction have appeared to coincide, and have commonly been confused. I shall discuss voluntary passivity and non-voluntary activity in turn.

It is a mistake to suppose that only activity can be voluntary. As it happens, the OED's entry for 'voluntary' begins with voluntary feelings and then proceeds to voluntary action; and if we turn to the entry for 'voluntarily', we find several quotations in which the word qualifies something passive, including the very first. Here are the first and the eighth:

c1374 CHAUCER Boeth. III. pr. xii. (1868) 103 Ther may no man douten, that thei ne ben gouerned uoluntariely. ... 1663 BP. PATRICK Parab. Pilgr. xiii. (1687) 87 At last he voluntarily, and without any compulsion but that of his Love, died upon a Cross.

The truth is that the distinction between what is and what is not voluntary applies to passivity and to inactivity in exactly the same way as it applies to activity. Children are sometimes picked up and carried voluntarily, they are sometimes kissed and tucked up in bed voluntarily, and they sometimes eat their green vegetables voluntarily. For their part, adults are sometimes voluntarily unemployed, sometimes voluntarily undergo surgical procedures, and sometimes die voluntarily, as Bishop Patrick says Christ did, and as the Italian poet and advocate of euthanasia Piergiorgio Welby did last year. There is no reason to deny that voluntariness can be attributed equally to all of these things; and there is no reason to think that it is a different attribute, depending on which of them we have in mind.

The idea that only actions can be voluntary - or only the things we do, as opposed to the things that happen to us or are done to us-is pure dogma. In fact, conditions such as exile and poverty can be voluntary, despite not being things we do, because they may be the result of a choice and not of force or compulsion, or undue influence by others, and the same is true of the kisses we give and also of the kisses we receive. Roughly, voluntariness is about choice versus compulsion, and a child can sometimes choose whether to be kissed or carried, just as it can sometimes choose what to eat. Equally, a man may allow himself to fall in love with a woman, in the knowledge that he could avoid falling in love with her if he chose to, or allow himself to fall asleep in the knowledge that he could avoid falling asleep if he chose to; or he may fall in love willy nilly, or fall asleep despite trying to remain awake. In the first case, he falls in love or 
falls asleep voluntarily, in the second case not. But falling in love and falling asleep are not actions, any more than falling down the stairs.

Why has voluntary passivity been ignored? One reason is that many philosophers are interested in the concept of voluntariness because of its importance in ethics and the philosophy of law. In fact, the concept of voluntary passivity plays an important rôle in moral and legal reasoning, notably where consent is involved, e.g. in connection with the law of rape. Nevertheless, voluntary passivity has proved to be less salient than voluntary activity in this context, perhaps in the case of law because of what is called the 'act requirement', the doctrine that criminal liability requires an act. ${ }^{12}$ However, the main reason is that the distinction between what is and what is not voluntary was regarded for three centuries as part of a story about the interaction between mind and body. The questions that exercised philosophers were not: what can the concept of voluntariness be applied to?, and how should it be defined? They were: what causes the kind of motion in our bodies that we regard as subject to our own direction and control?, and how does this kind of motion differ from blinking, sneezing, or the beating of the heart?

As is well known, the orthodox answer to these questions was that voluntary motion or voluntary action-motion and action were commonly equated - is caused by a special kind of conscious thought, which was sometimes called a volition or act of will. There is no need for us to examine this theory here. The point that concerns us is that it reinforced the tendency to neglect voluntary passivity. For if a man falls asleep voluntarily or dies voluntarily on a cross, the cause is unlikely to be a conscious thought. In fact it will probably be the same-tiredness in one case and asphyxiation in the other-whether he falls asleep or dies voluntarily or not. It was therefore hard to see that activity and passivity are equally capable of being voluntary, as long the theory of volitions prevailed. However, it must be acknowledged that some of the theory's most trenchant critics have also ignored voluntary passivity, or actually denied that it exists. ${ }^{13}$

\section{7.}

The other mistake that has contributed to the fallacy that the active/passive distinction and the voluntary/not voluntary distinction coincide is the

\footnotetext{
12 On this topic, see Duff 2004, 69-103.

13 Ryle 1949, 74; Geach 1960, 221-225; White 1985, 50; Geach, but cf. Anscombe $1957,49$.
} 
thought or assumption that action is always voluntary. Hobbes, Locke, Hume and Mill made this assumption, and it remained dominant in philosophy during the first half of the twentieth century. It was also made by many nineteenth- and twentieth-century jurists. ${ }^{14}$ By the nineteenth century, it commonly took the form of a definition. For example, Mill defines action as follows: 'What is an action? Not one thing, but a series of two things; the state of mind called a volition, followed by an effect. ${ }^{, 15}$ And Austin (the nineteenth-century jurist, not the twentieth-century philosopher) offers the following definition: 'A voluntary movement of my body, or a movement which follows a volition, is an act." ${ }^{16}$

If we recall that action is not limited to animals capable of acting voluntarily, it is obvious that these definitions cannot be right. But even if we confine ourselves to human action, they remain unconvincing. Some human action is voluntary; some is not. It is debatable how much choice voluntariness requires. But if we are compelled to perform a certain action, and cannot choose whether to do so or not, then we do not perform this action voluntarily-whether the compulsion is physical, psychological, moral, or of some other kind. Do we pay our taxes voluntarily? Does a man who hands over his wallet do so voluntarily, if he is threatened with a gun? Does a prisoner reveal the names of his associates voluntarily, if he does so under torture? Perhaps we cannot answer these questions in general terms, and need to know more about each particular case. But is should be beyond dispute that some actions are not voluntary.

Again, we are bound to ask why philosophers adhered to the mistake idea that action is always voluntary over such a long period. Part of the reason is that they concentrated exclusively on human action, and almost exclusively on actions that consist in a human being moving part of his own body - again because action was regarded as one aspect of the nexus between mind and body. The reason this matters is that although many of our actions are not voluntary, most of our actions that consist in moving parts of our own bodies are voluntary. For example, when we move our lips or our legs - e.g. when we are speaking or walking - these actions are mostly, although not invariably, voluntary. Sleep is the main exception to this rule. For example, if I pull the blanket across me in my sleep, or call

\footnotetext{
${ }^{14}$ See for example Williams 1978, ch.2, §2; Dias 1970, 252. See White 1985, 28ff for further references.

${ }^{15}$ Mill, 1973, 1.3.5.

${ }^{16}$ Quoted in White 1968, 5.
} 
out a name, this is an action of mine; but it is not a voluntary action, if I do it unconsciously.

Why are most actions of this kind voluntary? The reason is that one of the principal factors that cancels voluntariness is ignorance, as Aristotle pointed out; and it is unusual for us to be unaware of the motion of our limbs. Again, sleep is the main exception. Other kinds of action are quite different. For example, when I walk across the garden I may sometimes kill an ant by treading on it, although I have not done so voluntarily since I was a child. I take the step voluntarily, but I do not kill the ant voluntarily, because I am unaware of killing it. Since my step-takings and my armraisings are mostly voluntary, whereas my ant-killings are not, it is much easier to equate action and voluntary action if our attention is exclusively directed towards actions of this kind. ${ }^{17}$

This is part of the reason why action and voluntary action have been equated. But an equally important part of the reason is that the doctrine that matter is inert was accepted by several influential philosophers in the seventeenth century - including Descartes, Malebranche and Hobbes - and exerted an important influence on the way in which the relationship between action and voluntariness was understood. This comes out especially clearly in Locke's discussion about the source of our idea of active power-in other words, the observations or experiences that enable us to form this concept in our minds.

8.

According to Locke, the idea of power is indispensible in science, because it is, he says, 'a principal ingredient in our complex ideas of substances. ${ }^{, 18}$ For example, the liability of gold to be melted in a fire and to be dissolved in aqua regia are no less essential to our idea of gold than its colour and weight. And even colour and weight, Locke claims, will also turn out to be powers, if we consider their nature carefully. But if all the materials of reasoning and knowledge - all of our ideas - are ultimately derived from experience, as Locke insists they are, what are the sources in experience of the idea of power?

${ }^{17}$ I ignore the doctrine, defended by Anscombe and Davidson, that if someone performs one action by performing another action, for example, crushes an ant by taking a step, these are one and the same action. This doctrine is criticized in Alvarez \& Hyman 1998, 234f.

${ }^{18}$ Locke 1997, 2.21.3. 
Locke's answer depends on distinguishing between two complementary kinds of power: active powers are abilities to produce various kinds of change, whereas passive powers are liabilities to undergo various kinds of change. Action, which is the exercise of an active power, is the production of some kind of change; passion, which is the exercise of a passive power, is the undergoing of some kind of change. The origin of our idea of passive power is, Locke thinks, quite clear. The idea is produced in us by bodies, because we cannot avoid perceiving the changes that they undergo: 'and therefore with reason we look on them as liable to the same change'. But Locke claims that we cannot observe the production of a change in the same way. For example, when we see one ball strike another ball, and set it in motion, Locke says,

[the first ball] only communicates the motion it had received from another, and loses in itself so much, as the other received; which gives us but a very obscure idea of an active power of moving in body, whilst we observe it only to transfer, but not produce any motion. ${ }^{19}$

Observing interactions between bodies cannot therefore be the source of our idea of active power. Rather, Locke claims,

we have [this idea] only from reflection on what passes in ourselves, where we find by experience, that barely by willing it, barely by a thought of the mind, we can move the parts of our bodies, which were before at rest. ${ }^{20}$

Thus, according to Locke, our idea of active power is drawn from the experience of producing motion voluntarily ourselves. Moreover, although Locke wanted to retain the idea that natural kinds of substance have characteristic active powers, it follows from these considerations that strictly speaking voluntary action is the only action there is. For when bodies interact, motion is communicated, but it is not produced; and action, Locke insists, is the production of motion, or some other kind of change. The mere transfer of motion does not amount to action. All real action must therefore be voluntary action, consciously effected by the mind.

Locke's argument is unconvincing, because the distinction between transferring and producing motion is specious. There is certainly a difference between producing and transferring people or goods. For example, manufacturers produce goods whereas exporters transport goods from one

\footnotetext{
${ }^{19}$ Ibid., 2.21.4.

${ }^{20}$ Ibid., 2.21.4.
} 
place to another; and parents produce children whereas bus-drivers transfer them from one place to another. Now if a bus-driver transfers children from a school to a playing-field, the same children who embark at the school disembark at the playing-field. Not just the same number of children, but the very same children. (That generally matters quite a lot to their parents.) But suppose one ball strikes another similar ball, sets it in motion, and decelerates appreciably itself. Has motion been transferred or produced? How are we to decide? We cannot ask whether the second ball acquires the very same motion - not merely the same quantity of motion but, as it were, the very same package of motion - that the first ball loses, because motion is not a substance that can be packaged and then either handed over or witheld.

But if, as Locke says, the first ball loses the same quantity of motion as the second ball gains, is this not a reason for denying that motion has been produced? It is not; but we need to be clear about why not. It is tempting to point out that when a cannon is fired, motion is not transferred from the powder to the ball. But it would be easy to reply on Locke's behalf that although he should have based his argument on the conservation of energy instead of motion, his basic point is sound. So this objection would not take us far. The real reason why the fact that the first ball loses approximately the same quantity of motion as the second ball gains should not encourage us to say that motion has been transferred rather than produced is that there is no reason why the production of motion-i.e. action-should be in breach of whatever conservation laws are enshrined in physics. ${ }^{21}$

This is the crux of the matter. Locke denies that the first ball produces motion in the second ball because it 'loses in itself so much, as the other received', in other words, because the interaction between the balls conserves the total quantity of motion. But it follows that he can only acknowledge that the production of motion - in other words, action-has occurred if the total quantity of motion is not conserved, but increased. An action must therefore be a breach of or an exception to the laws of nature. In other words, it must be a miracle, an interference in the natural course of

${ }^{21}$ Interestingly, we distinguish between producing and transferring wealth in the way Locke wants to distinguish between producing and transferring motion. The rich man who leaves his money to his son merely transfers wealth from one person to another, but the entrepreneur (we say) actually creates wealth. The reason why we are able to think about wealth in this way is that there are no conservation laws in economicssomething we all have reason to be grateful for. 
events by a being with the strictly supernatural ability to inject motion into the natural world, rather than merely transferring it to something else.

Locke's conclusion, that we are acquainted with action by 'reflection on what passes in ourselves', is therefore unsustainable, since human beings do not have supernatural powers. If his argument were sound, it would really establish that miracles aside, action does not exist at all. Reflecting on Locke's argument from our present vantage-point, it is not difficult for us to see this, in particular, because we understand that the conversation of energy - one of great discoveries of nineteenth century physics - applies to our voluntary behaviour no less than to the behaviour of billiard balls. Since we understand this, we can see that Locke's argument is really eliminativist in tendency. It does not confine action to the mind: it excludes it from the natural world altogether.

I suggest we can draw three conclusions from this analysis of Locke's argument.

First, in Locke's thought, and in the empiricist tradition stemming from Locke, the idea that all action is voluntary did not arise out of a theory of the will. It arose from a combination of two things: first, the idea that matter is inert, never a source of motion or change in its own right; and second, a not yet fully naturalized conception of human beings. The first idea encouraged philosophers to eliminate action, while the second held them back. The point of equilibrium was the confused idea that all action is voluntary, consciously executed by the mind.

Second, if we accept this conception of matter, we must dispense with the idea of a body as a substance with the active power to produce change - that is to say, we must dispense with the idea altogether, and not merely in our conception of non-human beings. However, if we do not accept this picture, we remain free to acknowledge that action occurs constantly, some of it voluntary and some of it not, some of it by human beings and some of it not, some of it by living beings and some of it not.

Finally, there is no reason to think that we are acquainted with action by 'reflection on what passes in ourselves' when we move 'the parts of our bodies which were before at rest'. For we observe action constantly (unless matter is inert). We observe action whenever we observe the 'beginning' as Locke calls it, the bringing about or causing, of motion or of any other kind of change. And we observe this whenever we see someone walking or speaking; when we see birds building their nests or ants carrying fragments 
of food in their mandibles; when we feel the sun warming our skin or ice cooling our tongue; and when we see one ball set another ball in motion. ${ }^{22}$

9.

The third fallacy I want to discuss is the idea that action is a kind of motion, for example, motion in a special context, or with a special cause.

Suppose a student in a class raises her arm. How is her action, her raising of her arm, related to the upward motion of her arm? Many philosophers either claim explicitly or assume that they are identical. For example, when Donald Davidson considers the question of how actions should be located in space and time, he writes:

if a man's arm goes up, the event takes place in the space-time zone occupied by the arm; but if a man raises his arm, doesn't the event fill the zone occupied by the whole man? Yet the events may be identical. ${ }^{23}$

Again, David Armstrong writes:

The rising of my arm is the raising of my arm provided that it is part or the whole of a pattern of behaviour that has an objective...$^{24}$

We are not concerned now with the idea that the raising of my arm must be part of a pattern of behaviour with an objective. All that concerns us is the idea that when a person raises her arm, her raising of her arm and the motion of her arm are one and the same event. This cannot be right. For to raise one's arm is to cause one's arm to rise. The action is the causing of the motion; and the causing of the motion cannot be identical with the motion itself. It makes no difference what is raised. If I raise my hand, my glass and the nail on my little finger in a single gesture, my raising of my hand and of the nail are just as certainly distinct from the motion of my hand and the nail as my raising of my glass is from the motion of the glass, despite the fact that the hand and the nail are parts of my body whereas the glass is not.

${ }^{22}$ See G.E.M. Anscombe, 'Causality and Determination', repr. in E. Sosa and M. Tooley 1993 93; Strawson 1992, 119.

${ }^{23}$ Davidson 1980, 124.

${ }^{24}$ Armstrong 1968, 170. 
This was pointed out by several philosophers in the twentieth century. For example, Prichard (whose theory of action was confused on practically every other point) writes:

When I move my hand, the movement of my hand, though an effect of my action, is not itself an action, and noone who considers the matter carefully would say it was, any more than he would say that the death of Caesar, as distinct from his murder, was an action or even part of an action. ${ }^{25}$

Prichard may not be right in saying that the movement - that is, the motion - of my hand is an effect of my action. We shall consider this idea shortly. But he is surely right in saying that it is not itself an action. And of course it follows from this that it is not identical with my action of raising my hand, which self-evidently is an action.

A more abstract remark by Von Wright also implies that we cannot identify action and motion:

It would not be right, I think, to call acts a kind or species of events. An act is not a change in the world. But many acts may quite appropriately be described as the bringing about or effecting ... of a change. ${ }^{26}$

(Von Wright calls particular instances of action acts, rather than actions. I shall not follow him in this.) We can set aside for the moment the question of whether actions are or are not a kind or species of events. The immediate importance of this passage is that Von Wright saw-as Prichard had seen - that the student's raising of her arm and the motion of her arm cannot be the same event, any more than the murder of Caesar can be identical with his death. For the motion of her arm is a change in the world: it is a change in the position of her arm. But her raising of her arm-her 'act' - is not a change in the world. It is 'the bringing about or effecting ... of a change.'

Prichard and Von Wright both reject the idea that Davidson and Armstrong both endorse, namely, that when the student raises her arm, her action is identical with the motion of her arm. On this point, on which they are agreed, Prichard and Von Wright are surely right. And Prichard is right to point out that the relationship between the action and the motion is the same as the relation between the murder and the death. For the action in both cases is (as Von Wright puts it) the bringing about or effecting-i.e.

\footnotetext{
${ }^{25}$ Prichard 1968, 63.

${ }^{26}$ von Wright 1963, 35f.
} 
the causing - of a change, whereas the motion of the student's arm and Caesar's death are the changes effected or brought about. And these cannot be the same. The causing of a change cannot be identical with the changed caused, because causation is a genuine relation, which holds between distinct particular objects or events, just as spatial and temporal relations do.

Compare causing a change with taking a bath or meeting one's death. The phrases, 'take a bath' and 'meet one's death' are examples of a fairly common construction in English. One can take a bath and have a chat; one can make a choice or a promise; and so on. Often the verb is 'have', 'do', 'give', 'make' or 'take'. But it is sometimes cognate with the noun-phrase. For example, if Socrates lived well and died peacefully, then he lived a good life and died a peaceful death. The construction is common because it is often convenient to qualify a noun with an adjective instead of qualifying a verb with an adverb, but it is merely a syntactic expedient, in the sense that the verb does not express a genuine relation. On the contrary it refers to one of the very things that it appears, syntactically, to relate. For example, if one takes a bath, the taking of it is the bath one takes; and when Socrates met his death, their meeting was his death.

Thus, in such cases, the taking or the meeting can be identified with what is taken or met. But an action - the causing of a change - cannot be identified with the change caused, because causation is a genuine relation. In this respect, it is like the taking that occurs if one takes a chocolate rather than a bath, or the meeting that occurs if one meets a friend rather than one's death. ${ }^{27}$

So the student's raising of her arm cannot be identified with the motion of her arm. Why then did philosophers confuse them? One reason is the tendency, mentioned earlier, to focus on actions that consist in a human being moving part of his own body. For the distinction between action and motion is less salient in this kind of case. For example, it is much easier to confuse someone's raising of her arm and the motion of her arm than it is to confuse someone's raising of a flag and the motion of the flag, because in the latter case we can imagine the motion without the action. We can cut the agent out of the picture, so to speak. But if the thing that moves is part of the agent's body, we cannot do this; and if we imagine ourselves pointing to the action and pointing to the motion, we shall imagine ourselves pointing to roughly the same place.

But there is also a deeper reason for the confusion, namely, the assumption that actions are events.

${ }^{27}$ I disucss this issue in more detail in Hyman 2001, 298-317. 


\section{0.}

'It would not be right ...' Von Wright says, 'to call acts a kind or species of events.' If this were merely a terminological remark, we could bat it away. Whether actions should be called events, we could say, depends on how inclusive a category of events one has in mind. But in fact the remark is not merely about what actions should be called: it is about what actions are. We have already seen that the action of raising an arm cannot be identified with the motion of the arm, any more than the action of killing Caesar can be identified with the death of Caesar. The causing of a change, we said, is not that change itself. Von Wright's remark implies that the action is not an event that causes the motion of the arm or Caesar's death either, and this claim is not merely about words. I believe it is right, for two reasons, one grammatical and the other epistemological.

The grammatical reason concerns the fact that the word 'causing' in the phrase 'a causing of a change' is what grammarians call a nominalization, that is, a noun or noun phrase derived from another part of speech. The nouns 'kiss' in the phrase 'the kiss Mark gave Sharon' and 'love' in the phrase 'Tom's love for Lucy' are other examples. Now we can use the phrase 'the kiss Mark gave Sharon' to refer to the action reported in the sentence 'Mark gave Sharon a kiss' - the giving of the kiss and the kiss given being identical, just as the taking of a bath and the bath taken are; and we can use the phrase 'Tom's love for Lucy' to refer to the relation (strictly speaking, the relation-instance) reported in the sentence 'Tom loves Lucy'. Clearly the phrase 'the kiss Mark gave Sharon' does not refer to an object or event that kissed Sharon, and the phrase 'Tom's love for Lucy' does not refer to an object or event that loves Lucy. The kiss is not the one that kisses and the love is not the one that loves. It is the action or relation itself, and not the agent or one of the relata.

The same applies in the case of 'killing', 'turning', 'causing', and so on. 'Brutus's killing of Caesar' refers to the action reported in the sentences 'Brutus killed Caesar', and 'Paul's turning of his head' refers to the action reported in the sentence 'Paul turned his head'. But again, these phrases do not refer to objects or events that killed Caesar and turned Paul's head. In fact we can state a general principle, that where ' $a$ ' and ' $b$ ' are names of particulars (of whatever categories or kinds) and ' $\{$ verb $\}$ ' stands for a verb or verb phrase, ' $a$ 's \{verb \}ing of $b$ ' does not refer to an object or event that $\{$ verb $\} s b$. In every case, it refers to the action or the relation and not to the 
agent or one of the relata. This principle is not merely about words. The phrase ' $a$ 's causing of $b$ ' refers to $a$ 's causing of $b$. Hence if ' $a$ 's causing of $b$ ' does not refer to an object or event that causes $b$, then $a$ 's causing of $b$ is not an object or event that causes $b$. In short, a causing is not a cause.

Furthermore, many of the verbs we use to refer to actions can also be used, without any change of meaning, to refer to relations between events. For example, the verb 'rock' has exactly the same meaning in the sentences 'Mary rocked the cradle' and 'The explosion rocked the building': in both cases, it means 'cause to rock', in conformity with the pattern described in section (2). Hence, if the phrase 'Mary's rocking of the cradle' refers to an event that causes the motion of the cradle, the phrase 'the explosion's rocking of the building' must refer to an event that causes the motion of the building - a third event, in addition to the explosion and the motion of the building. And if this third event causes the rocking of the building, that is, if it rocks it, the phrase 'the third event's rocking of the building' must refer to a fourth event, which also causes the motion of the building. And so on ad infinitum. An infinity of such events may not be a logical or physical impossibility; but the idea that these mundane statements imply that infinities of such events occur is surely absurd.

Thus, we only need to consider the grammar of nominalizations to see that Prichard was mistaken in thinking that when I move my hand, the motion of my hand is an effect of my action. Now some philosophers are inclined to dismiss arguments that appeal to grammar with a vague mention of differences between 'superficial' grammatical form and 'deep' logical form. The reply is simple. The distinction between grammatical form and logical form is real, but it cannot be used in this way. For if a philosophical doctrine implies something false then it is must be false, and if it is implied by something true then it must be true, regardless of the subject-matter of the truth or falsehood concerned. If a philosopher proves the existence of God from the premise that ginger is hot, we cannot object that this is merely a fact about root vegetables. Equally, if a philosophical doctrine implies that nominalizations of verbs such as 'love', 'kiss', 'kill' or 'cause' refer to things that love, kiss, kill or cause, it cannot be defended on the grounds that the behaviour of these parts of speech is mere grammar.

The epistemological reason why the causing of a change cannot be an event that causes the change is this. If a student's raising of her arm were an event that causes the motion of her arm, it would be an event that occurs inside her body: a contraction of a muscle or a release of a neurotransmitter, or some other kind of event in the agent's nervous system. For these 
are the events that cause the motion of a person's arm, when she raises it. But if the student's action were an event that occurs inside her body, we would not be able to see it. The action, as opposed to its effect, would be hidden from view. One might think that this would not present a serious practical difficulty, since we would still be able to see her arm go up. But that is not to the point. For the point is that we do witness actions of this kind, and not merely their effects. If I say that I saw someone raise her arm, wave her hand or turn her head, my statement may be true, without being an elliptical or inaccurate way of saying that I saw an event that was caused by one of these actions.

Despite this formidable difficulty, the view that actions occur inside the agent's body has been seriously advanced. Jennifer Hornsby, who advances it, replies to the objection as follows:

... the objector thinks that we see actions themselves, and I am inclined to agree. But he says 'If actions are inside the body, then we cannot see them.' Some doubt is cast on his conditional when we remember that to say that actions take place inside the body is not to deny that they take place in larger portions of space ... Perhaps then we see actions in virtue of seeing some place where they occur when they occur; perhaps we see actions in virtue simply of seeing the people whose actions they are at the time of their happening. Or again, perhaps we see actions in seeing their effects. ${ }^{28}$

Hornsby does not say which of these alternatives she prefers; but none of them can be right. For we do not see events in a person's nervous system 'in virtue of seeing' some place where they occur when they occur, any more than we see a man walking in Hyde Park in virtue of seeing Hyde Park while he is walking there. We do not see an event in someone's nervous system 'in virtue simply of seeing' him when the event occurs, any more than we see a door open inside a house in virtue simply of seeing the house when the door opens. And we do not see events in a person's nervous system 'in seeing their effects', any more than we see the pistons of an engine move in seeing the car accelerate along a highway. Hence, no doubt is cast on the objector's conditional by the alternatives canvassed here, and the objection stands. ${ }^{29}$

\footnotetext{
${ }^{28}$ Hornsby 1980, 103.

${ }^{29}$ On the visibility of action, see the exchange between Lowe and Hornsby published in Analysis: E.J. Lowe, 'All Actions Occur inside the Body', 41 (1981); Hornsby, 'Reply to Lowe on Actions', 42 (1982); Lowe, 'Reply to Hornsby on Actions', 43 (1983); Hornsby, 'Events that are Causings: A Response to Lowe', 43 (1983); Lowe, 'A Note
} 
For these reasons, it is not only a mistake to identify the causing of a change with that change itself; it is also a mistake to identify it with another event that causes it. The action of raising one's arm is not an event that causes the motion of one's arm, the action of killing Caesar is not an event that causes Caesar's death, and so on. However, philosophers during the last three centuries have mostly failed to distinguish between my raising of my arm, which is an action, and the motion of my arm, which is an event. And when the action and the motion are not simply identified-as they are by Austin, Davidson and Armstrong - the action is either identified with the cause of the motion, as it is by Prichard and Hornsby, or with a combination of the motion and its cause, as it is by Mill. ${ }^{30}$ Staring myopically at a sequence of events-like Edwin Abbot's Flatlanders-all of these philosophers felt compelled to locate the action somewhere along its length. ${ }^{31}$

Hence, let us suppose - to take another well-known example - that a queen kills a king by pouring poison into his ear. We can imagine tracing our way back from the king's death along the chain of causally related events that led up to it - events that occurred inside the king's body as the poison took effect, earlier events that occurred in the space between his body and the queen's body, such as the motion of the phial beside his ear, and yet earlier events that occurred inside the queen's body, such as the contraction of a muscle and the release of a neurotransmitter. But it follows from these arguments that we shall not find either the queen's killing of the king or her pouring of the poison into his ear anywhere along this chain of events. The queen's killing of the king is (roughly speaking) the causal relation between her and one of these events, namely, the king's death, and

on a Response of Hornsby's', 44 (1984). More recently, Hornsby has argued that actions may after all be invisible; and that a theory of action can safely ignore the question of whether it implies that they are. See Hornsby 1997, 99. However, if, as Hornsby explicitly acknowledges, 'people see one another doing things' (ibid., 97), the proposition that actions are visible is not merely an intuition: it is a fact.

${ }^{30}$ But see von Wright 1963, ch.3; Bach 1980, 114-20; Alvarez \& Hyman 1998, 219245; Alvarez 1999, 213-239.

${ }^{31}$ Davidson's article 'The logical form of action sentences' (repr. in Davidson 1980) persuaded many philosophers that actions are events. However, the most effective formalization of action sentences - i.e. the one that best preserves the inferences we independently recognize as due to form - quantifies over the changes agents cause, and not over their their actions. (See Alvarez 1999, passim.) Hence, Davidson's dubious view that formal logic is a guide to metaphysics does not support the doctrine that actions are events. 
not one of the events themselves; and her pouring of poison into his ear is the causal relation between her and an earlier event in the same chain, namely, the poison's entering his ear.

This, as I see it, is the point of insisting, with Von Wright, that it would not be right to call acts a kind or species of events. We remain free, of course, to state the same point in another way, e.g. by denying that actions are changes, while including both actions and changes in a broader category of events. But this is merely a terminological choice. The choice can perhaps be supported or opposed by evidence about our habitual use of words. But a debate of this sort is likely to be inconclusive. For although Von Wright's distinction between a change in the world and the bringing about or effecting of a change - or between an event and the causing of an event - is of real importance for philosophical purposes, it can safely be ignored for most other purposes. And besides, our choice of terminology cannot affect the substantial point, that the action of moving or changing something in some way is neither this motion or change itself, nor an event that causes it to occur.

As simple as it may appear, this point has proved remarkably elusive. For example, having distinguished between transitive and intransitive occurrences of verbs such as 'move', 'break', 'burn', 'melt', etc., and using the subscripts ' $\mathrm{T}$ ' and ' $\mathrm{I}$ ' to indicate which kind of occurrence she has in mind, Hornsby writes:

Where ' $a$ ' designates something in the category of a continuant (rather than event), it is a necessary condition of the truth of ' $a \varphi_{\mathrm{T}}$-s $b$ ' that $a$ cause $b$ to $\varphi_{\mathrm{I}}$. In that case movements $\mathrm{T}_{\mathrm{T}}$ of the body are events that cause bodily movements $\mathrm{s}_{\mathrm{I}}$.

The italics in this passage are original, but it is really the phrase 'in that case' that should be italicized, because the non sequitur is startling. As we have seen, Hornsby is right not to identify bodily movements $\mathrm{T}_{\mathrm{T}}$ with bodily movements $_{[}$- e.g., Paul's turning of his head with the motion of Paul's head. Her mistake is to assume that Paul's action belongs to the sequence of causally related events which includes the motion of his head. It is this assumption that makes it seem that if bodily movements $\mathrm{T}_{\mathrm{T}}$ are not identical with bodily movements then they must be among their causes. For they are evidently not among their effects. ${ }^{32}$

\footnotetext{
${ }^{32}$ Notice that Hornsby's first claim, that 'it is a necessary condition of the truth of " $a$ $\varphi_{\mathrm{T}}-\mathrm{S} b$ " that $a$ cause $b$ to $\varphi_{\mathrm{I}}$ ', is confined to the case where ' $a$ ' designates a continuant. Why are events excluded? If 'Matthew rocked the cradle' implies that Matthew caused the cradle to rock, why does 'The explosion rocked the building' not imply that the
} 
There is nothing especially puzzling about the concept of action, as long we understand that it is a broad causal concept which applies across the natural world, and as long as we keep the active/passive distinction and the voluntary/not voluntary distinction firmly apart, and avoid confusing actions and events. An action is simply the exercise of an active power, an ability to produce some kind of change. The answer to Wittgenstein's famous question, What is left over if I subtract the fact that arm goes up from the fact that I raise my arm? is not willing, intending, trying, or any other kind of mental cause; but it is not nothing either, or (as Wittgenstein intimates) the absence of surprise. What is left over is the fact that I made it happen, the fact that I caused the motion of my arm to occur. Nothing could be simpler. But the three fallacies I have discussed prevented philosophers from understanding action for three centuries, and they continue to exercise an extraordinary grip on the philosophy of action to this day. Furthermore, they not only prevent us from understanding action, they also lead inevitably to misunderstandings about willing, intending and trying. I shall leave the task of demonstrating this for another occasion. ${ }^{33}$

explosion caused the building to rock? I would say that it does imply this. But when we move on to the second quoted sentence, we can see Hornsby's reason for excluding events. For if the first claim applied to events, the second would too-i.e. Hornsby would be bound to hold that movements $_{\mathrm{T}}$ by events are also events that cause movements ${ }_{I}$. For example, when an explosion rocks a building the rocking I $_{\mathrm{I}}$ of the building is caused by the explosion; but on this view it is also caused by the explosion's rocking $_{\mathrm{T}}$ of the building. This raises the question: if this event causes the rocking $\mathrm{I}_{\mathrm{I}}$ of the building, does it rock $_{\mathrm{T}}$ the building? If so, an infinite regress is in train; if not, how is the distinction between rocking ${ }_{\mathrm{T}}$ and causing to rock $_{\mathrm{I}}$ to be explained? This quandary provides Hornsby with a motive for confining the claim that 'it is a necessary condition of the truth of " $a \varphi_{\mathrm{T}}$-s $b$ " that $a$ cause $b$ to $\varphi_{\mathrm{I}}$ ' to the case where ' $a$ ' designates a continuant; but it does not provide a justification for doing so.

${ }^{33}$ I am grateful to Maria Alvarez and Peter Hacker for their comments on an earlier draft of this paper. 


\section{REFERENCES}

Alvarez, M. 1999 “Actions and events: some semantical considerations”, Ratio, 12, 213-239.

Alvarez, M. \& Hyman, J. 1998 “Agents and their Actions”, Philosophy, 73, 219-245.

Anscombe, G.E.M. 1957 Intention, Oxford: Blackwell.

- 1981 "Causality and Determination", repr. In Anscombe, Metaphysics and the Philosophy of Mind, Oxford: Blackwell.

Armstrong, D. 1968 A Materialist Theory of the Mind, London: Routledge \& Kegan Paul.

Bach, K. 1980 “Actions are not events", Mind, 89, 114-20

Broadie, S. 1991 Ethics with Aristotle, Oxford: OUP.

Davidson, D. 1980 Essays in Actions and Events, Oxford: OUP.

Dias, R.W.M 1970 Jurisprudence, London: Butterworths.

Duff, A. 2004 "Action, the act requirement and criminal liability", in J. Hyman and H. Stewart (eds.), Agency and Action, Cambridge: CUP.

Fodor, J. 1976 The Language of Thought, Hassocks: Harvester.

Geach, P.T. 1960 “Ascriptivism”, The Philosophical Review, 69, 221-225.

Grice, H.P. 1989 Studies in the Way of Words, Cambridge, Mass.: Harvard.

Hornsby, J. 1980 Actions, London: Routledge \& Kegan Paul.

- 1997 Simplemindedness, Cambridge, Mass.: Harvard U.P.

Hyman, J. 2001 "-ings and -ers", Ratio (new series), 14, 298-317.

Kenny A.J.P. 1975 Will, Freedom and Power, Oxford: Blackwell.

Levin, B. 1993 English verb classes and alternations, Chicago: Univ. of Chicago Press.

Locke, J. 1997 An Essay Concerning Human Understanding, ed. R. Woolhouse, London: Penguin.

Mill, J.S. 1973 A System of Logic, Ratiocinative and Deductive, ed. J.M. Robson, Toronto: Univ. of Toronto Press.

Prichard, H.A. 1968 "Acting, Willing, Desiring", repr. in A.R. White (ed.), The Philosophy of Action, Oxford: OUP.

Ryle, G. 1949 The Concept of Mind, London: Hutchinson.

Sosa, E. and Tooley, M. (eds.)1993 Causation, Oxford: OUP.

Strawson, P. 1992 Analysis and Metaphysics, Oxford: OUP.

von Wright 1963 Norm and Action, London: Routledge \& Kegan Paul.

White, A.R. 1968 The Philosophy of Action, Oxford: OUP.

- 1985 Grounds of Liability, Oxford: OUP.

Williams, G. 1978 Text Book of Criminal Law, London: Stevens. 